DOI: $10.34185 / 1991-7848.2019 .01 .06$

УДК $629.7: 658.512 .2$

П.Т. Мельянцов, О.М. Лосіков, В.Ф. Мовчан

\title{
КОНСТРУКТИВНІ РІШЕННЯ ПО ЗНИЖЕННЮ ОБ'ЄМНИХ ВТРАТ РОБОЧОЇ РІДИНИ В ШЕСТЕРЕННИХ НАСОСАХ ПІДЖИВЛЕННЯ АКСІАЛЬНО- ПОРШНЕВИХ ГІДРОМАШИН
}

\begin{abstract}
В мобільних машинах гірничо-металургійного комплексу має місце застосування об'ємних гідравлічних трансмісій, що значно покращує їх керованість та мобільність в процесі роботи. Розглядаються конструктивні рішення по зниженню об'ємних втрат робочої рідини в шестеренних насосах підживлення аксіально-поршневих гідромашин. Мета дослідження - збільшення експлуатаційної довговічності насосів підживлення аксіальнопоршневих гідромашин розробленням конструктивних заходів по зниженню об'ємних втрат в його качаючому вузлі. Запропоновано спосіб компенсації торцевого зазору 3 застосуванням пластини компенсації торцевого зазору, що складається з робочої поверхні і пружнодемпфуючого елемента, у якому додатково розташовані канали й камери гідростатичного піджиму. Проведено аналіз сил, що діють на пластину компенсації торцевого зазору $i$ обгрунтовано їх оптимальне співвідношення, яке забезпечує величину торцевого зазору, що обумовлює мінімальні об'ємні втрати робочої рідини в качаючому вузлі насосу підживлення і забезпечує збільшення його експлуатаційної довговічності.
\end{abstract}

Ключові слова: об’ємні втрати, насос підживлення, довговічність.

\section{Постановка проблеми}

Одним із конструктивних заходів, який широко реалізується в мобільних машинах, що використовуються в гірничо-металургійному комплексі, являється застосування об’ємних гідравлічних трансмісій, що значно покращує їх керованість та мобільність в процесі роботи.

Основними складовими гідрофікованих трансмісій являються аксіальнопоршневі гідромашини (регульований аксіально-поршневий гідронасос $\mathrm{i}$ не регульований аксіально-поршневий гідромотор). В свою чергу, до конструктивних особливостей аксіально-поршневих гідронасосів слід віднести застосування насоса підживлення шестеренчастого типу, який служить для запуску гідроприводу, забезпеченню тиску робочої рідини в магістралі керування робочим об'ємом основного насоса і компенсації втрат робочої рідини в об’ємних гідромашинах.

$€$ очевидним, що зміна технічного стану насоса підживлення буде суттєво впливати на роботоздатний стан, як аксіально-поршневого гідронасоса так і на гідравлічну трансмісію в цілому.

Результати досліджень експлуатаційної надійності насосів підживлення в роботах [1,2], показали, що до основних причин, які обумовлюють втрату їх

(c) Мельянцов П.Т., Лосіков О.М., Мовчан В.Ф., 2019 
роботоздатності, слід віднести гідроабразивне зношення деталей в спряженнях: «торець шестерні-верхня кришка», «торець шестерні-нижня кришка», «колодязь корпусу-зуб шестерні». Зміна структурних параметрів деталей в перших двох спряженнях обумовлює зростання торцевого зазору в качаючому вузлі насоса, а в спряженні «колодязь корпусу-зуб шестерні» - радіального зазору. Збільшення зазорів в даних з'єднаннях обумовлює зростання об’ємних втрат робочої рідини, а значить приводить до зменшення подачі насоса $(Q)$ л/хв і об'ємного коефіцієнта корисної дії $\eta$.

При цьому в роботі [3], автор відмічає, що близько $40 . .65$ \% об’ємних втрат робочої рідини в качаючому вузлі шестеренного насоса припадає на торцевий зазор, i близько $22 . . .30$ \% на радіальний зазор, від загального об’єму втрат рідини в залежності від зазору.

Водночас, проведений аналіз конструктивних особливостей насоса підживлення аксіально-поршневих гідромашин в роботах [4,5], показав, що в його качаючому вузлі відсутні конструктивні рішення з компенсації торцевого і радіального зазорів, що суттєво впливає на його експлуатаційну довговічність.

В зв'язку 3 цим питання забезпечення зростання довговічності насосів підживлення аксіально-поршневих гідромашин, за рахунок стабілізації торцевого і радіального зазору в його качаючому вузлі, являються актуальними та потребують детального дослідження.

\section{Аналіз останніх досліджень та публікацій}

Системи компенсації торцевого і радіального зазору реалізовані в качаючому вузлі шестеренного насосу модифікації НШ-К [6]. Для компенсації «торцевого зазору», в качаючому вузлі застосовуються «платики-замикачі» 3 манжетами, а для «радіального зазору» - підтискна обойма 3 манжетою радіального піджиму, яка розміщується в корпусі насоса.

Впровадження аналогічних конструктивних рішень в насосі підживлення не можливе, так як за конструктивним рішенням його качаючий вузол суттєво відрізняється від качаючого вузла насоса модифікації НШ-К.

Більш прогресивною конструкцією шестеренної гідромашини, являється конструкція насосу НШ-50В, яка запропонована в роботі [6] і створена на базі насоса НШ-46У. Перевагою ï в порівнянні $з$ конструкцією насоса НШ-50К, являється менша вага і простота в виготовленні, так як ведена і ведуча шестерні обертаються в чотирьох підшипниках ковзання, а для компенсації торцевого зазору застосовується П-подібна еластична манжета, яка підтискає пластини - компенсатори до торцевих поверхонь шестерень. До недоліків запропонованої конструкції слід віднести те, що П-подібна еластична манжета обмежує лише зону високого тиску, що в процесі роботи насоса може викликати перекошення пластин-компенсаторів і зниження його довговічності. 
Проведений аналіз існуючих конструктивних рішень компенсації «торцевого зазору» в качаючому вузлі шестеренного насосу, показав, що для насосу підживлення необхідне інше рішення. Це також обумовлюється тим, що за конструктивним рішенням, у насоса підживлення потік робочої рідини від забірного отвору до нагнітаючого відрізняється від потоку робочої рідини у типових шестеренних насосів, де він перпендикулярний по відношенню до вісей шестерень качаючого вузла.

Механізми компенсації радіального зазору в шестеренних насосів модифікації НШ-У, до яких максимально наближається конструкція насосу підживлення, в основному зводиться до забезпечення жорсткості в підшипникових вузлах ковзання, для запобігання переміщення шестерень і вісей качаючого вузла, під тиском робочої рідини зони високого тиску, до отвору забірної магістралі.

На сьогоднішній день дане питання вирішується за рахунок застосування в якості підшипників ковзання бронзових втулок, які безпосередньо встановлюються в корпус гідронасоса. При цьому їх реалізація ефективна при роботі насоса в режимі рівномірних кутових навантажень на ведучу шестерню при запуску насосу. За умови виникнення статодинамічного режиму навантаження на ведучу шестерню, різко зростають питомі навантаження в спряженні «цапфа шестерні-втулка», що приводить до значного зношення деталей і відповідно до зростання радіального зазору.

\section{Мета дослідження}

Мета дослідження - збільшення експлуатаційної довговічності насосів підживлення аксіально-поршневих гідромашин розробленням конструктивних заходів по зниженню об’ємних втрат в його качаючому вузлі.

\section{Викладення основного матеріалу дослідження}

Раніше в роботі [3], відмічалось, що витоки робочої рідини через торцеві зазори являються найбільш вагомими і при збільшенні зазору на 0,1 мм в типовому насосі об’ємний коефіцієнт корисної (ККД) дії зменшується на 25 \%.

3 метою зменшення об’ємних втрат робочої рідин і одночасно механічних втрат на тертя, пропонується нова конструкція торцевих ущільнень шестеренного насоса підживлення аксіально-поршневого гідронасоса (рис.1, рис.2).

Шестеренний насос підживлення аксіально-поршневої гідромашини включає в себе корпус 1 , верхню 2 та нижню 3 кришки в розточках яких розміщені ведена 4 й ведуча 5 шестірні. Ведуча шестірня 5 спряжена через шпонку 63 валом 7, ведена 4 встановлена вільно на осі 8. У верхній кришці 2, встановлена пластина 9 компенсації торцевого зазору, яка складається з робочої поверхні 10, опорної поверхні 11 та пружнодемпфуючого елемента 12, у якому розташовані канали 13 й камери 14 гідростатичного піджиму. Камери 14 гідростатичного піджиму розташовані зі сторони верхній кришки 2 під кутом 90 та сполучені між собою каналами 13, які з'єднані отворами 15 з камерою нагнітання 16. 


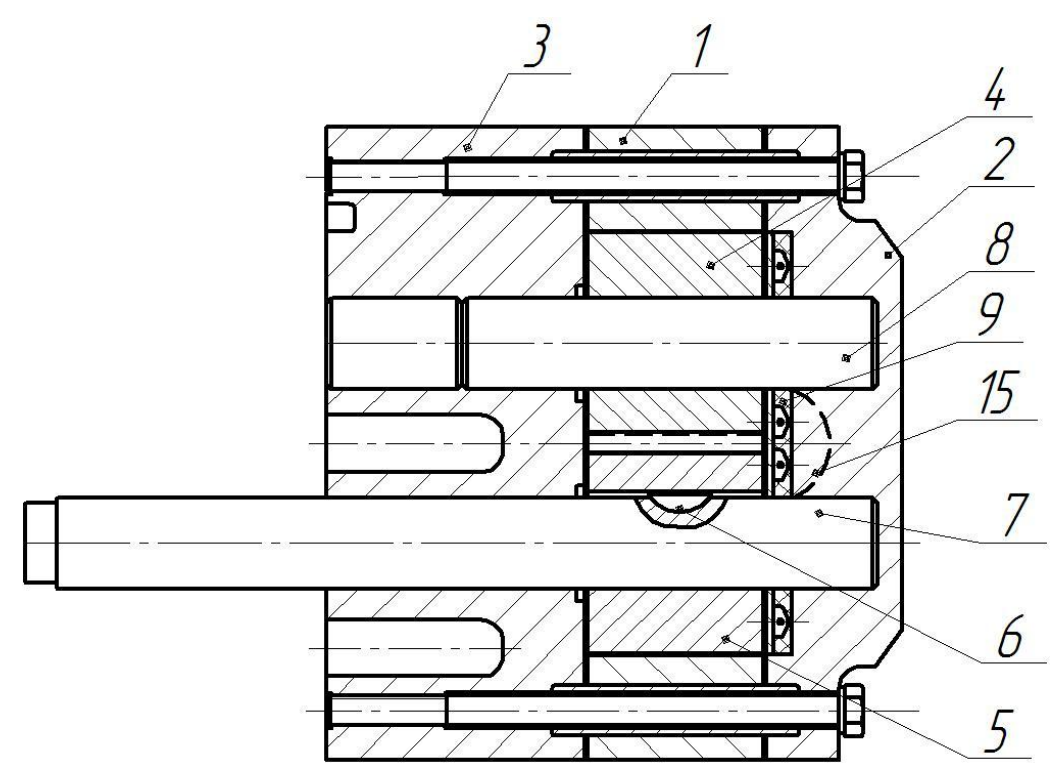

Рисунок 1 - Насос підживлення з торцевим ущільненням

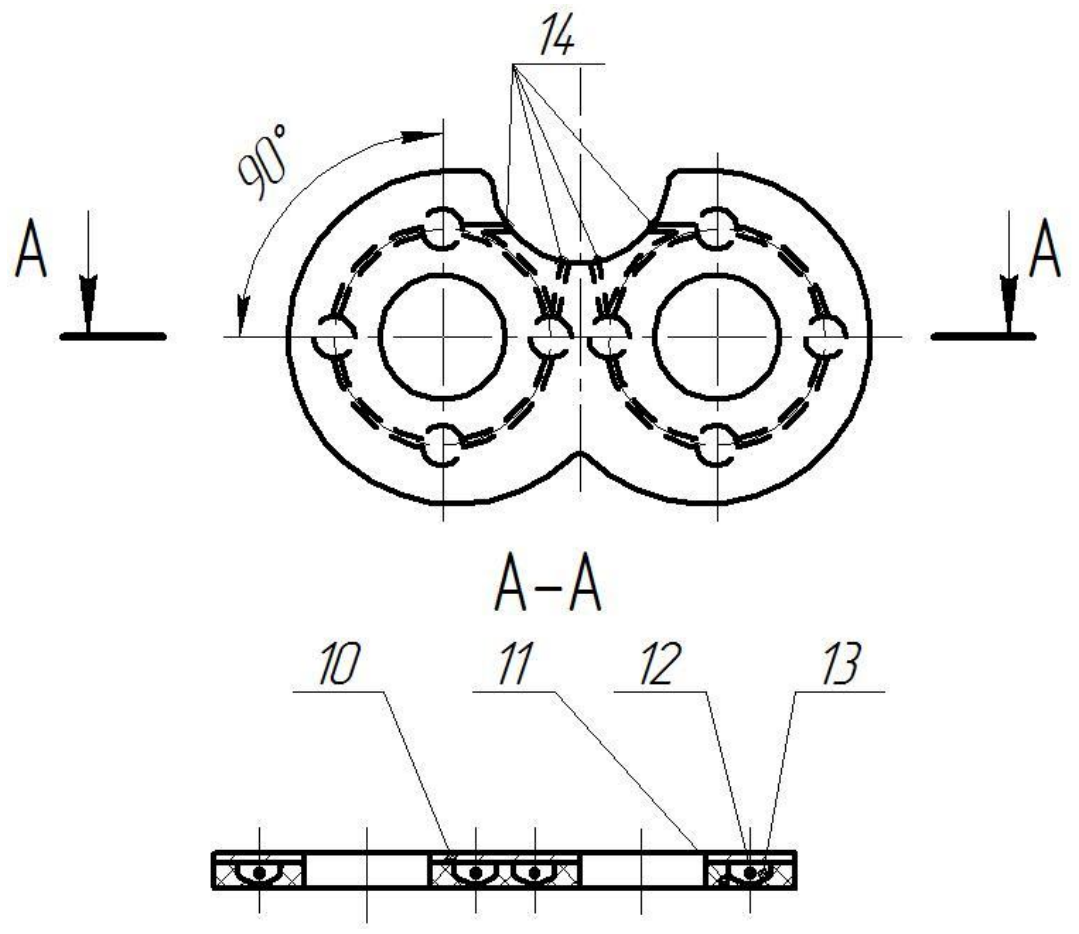

Рисунок 2 - Конструкція пластини компенсації торцевого зазору

При роботі насоса підживлення робоча рідина із камери нагнітання 16 , поступає до основного насосу аксіально-поршневої гідромашини і одночасно до отворів 15 пружнодемпфуючого елемента 12 пластини 9 і по каналах 13 надходить до камер 14 гідростатичного піджиму. Поступаючи в замкнутий простір камер гідростатичного піджиму під тиском, робоча рідина обумовлює переміщення опорної поверхні 11 пластини гідростатичного піджиму до кришки 2, а робочої поверхні 10 до торців шестерень 4 та 5, за рахунок тиску робочої рідини та пружних властивостей пружнодемпфуючого елемента, компенсуючи таким чином торцевий зазор між торцями шестерень та робочою поверхнею 10 пластини 9. Враховуючи те, що шестерні рухливі в осьовому напрямку, вони переміщуються під дією тиску робочої поверхні 10 
пластини 9 до нижньої кришки 3, що забезпечує компенсацію торцевого зазору між нижньою кришкою 3 та торцем шестерень 4 і 5, і збільшує коефіцієнт подачі насоса та його довговічність.

Отже переміщення пластини компенсації торцевого зазору до торців шестерень забезпечується за рахунок гідростатичного піджиму за допомогою рідини, яка подається з камери високого тиску. В даному випадку важливим буде зусилля з яким пластина буде підтискатись до торцевої частини шестерні.

При недостатньому зусиллі притискання будемо мати значні об'ємні втрати робочої рідини, а при значних зусиллях можуть виникнути умови граничного тертя між робочою поверхнею пластини та торцем шестерень, що буде обумовлювати механічні втрати.

Робота сил тертя між торцем шестерень і робочою поверхнею пластини компенсації торцевого зазору визначається за виразом:

$$
A_{\text {mep }}=F_{\text {mep }} \cdot L_{\text {mep }} \text {, }
$$

де $F_{\text {тер }}$ - сила тертя, $\mathrm{H}$;

$L_{\text {mер }}$ - шлях тертя, м.

Аналіз виразу (1) показує, що робота сил тертя $\left(A_{\text {mер }}\right)$ знаходиться в прямопропорційній залежності від сили тертя $\left(F_{\text {mер }}\right)$ і шляху тертя $\left(L_{\text {тер }}\right)$.

В свою чергу, шлях тертя обумовлюється геометричними розмірами торцевої поверхні шестерні, яка контактує з притискною пластиною. 3 врахуванням того, що у насосів підживлення в процесі експлуатації виникає в основному параметрична відмова, яка характеризується поступовою зміною структурних параметрів технічного стану робочих поверхонь деталей, будемо вважати, що шлях тертя являється постійною величиною.

Звідси випливає, що на роботу сил тертя в спряженні «поверхня притискної пластини - торець шестерні» в своїй більшості буде впливати сила тертя $\left(F_{\text {mер}}\right)$.

Сила тертя визначається за виразом:

$$
F_{\text {mep }}=N_{n p .} \cdot f,
$$

де $N_{n p}$ - сила притискання пластини компенсації торцевого зазору до торцевої поверхні шестерні, $\mathrm{H}$;

$f$ - коефіцієнт тертя, який залежить від виду тертя між робочими поверхнями.

$€$ очевидним, що для зменшення сили тертя в спряженні необхідно в першу чергу передбачити рідинний вид тертя, який буде характеризуватися наявністю масляної плівки між поверхнями тертя. Отже значення коефіцієнта тертя $(f)$ буде відповідати рідинному виду тертя.

В якості критерію, для визначення мінімального значення торцевого зазору в спряженні «поверхня притискної пластини - торець шестерні», візьмемо геометричний розмір абразивних частиць (50 мкм), кількість яких максимальна для 
десятого класу чистоти робочої рідини [7], на якій в відповідності до технічних вимог, експлуатуються аксіально-поршневі агрегати гідравлічних трансмісій.

Таким чином мінімальне значення торцевого зазору буде залежати від співвідношення сили притискання $\left(N_{n p}\right)$ пластини до торцевої частини, і сил відтискання $\left(N_{\text {від }}\right)$, які будуть відтискати пластину від торцевої поверхні шестерень.

Сила притискання $\left(N_{n p}\right)$ пластини компенсації торцевого зазору визначиться за виразом:

$$
N_{n p}=\left(n_{\text {кам }} \cdot S_{\text {кам }}+S_{\text {кан }}\right) \cdot P_{\text {нм }},
$$

де $n$ - кількість камер гідростатичного піджиму в пластині компенсації торцевого зазору, од.;

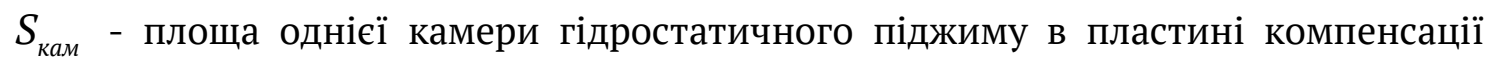
торцевого зазору, $\mathrm{M}^{2}$;

$S_{\text {кан }}$ - площа каналів, що розміщуються в пружнодемпфуючому елементі пластини, для підводу робочої рідини до камер гідростатичного піджиму, $\mathrm{M}^{2}$;

$P_{\text {нм }}$ - значення тиску в нагнітаючій магістралі насоса підживлення, МПа.

Враховуючи те, що максимальний тиск в нагнітаючій магістралі насоса обмежується запобіжним клапаном, який безпосередньо розміщений в насосі, i відповідає значенню $P_{\text {нм }}=1,40 M П а$, то в відповідності 3 виразом (3), сила притискання $\left(N_{n p}\right)$ буде залежати від сумарної площі поверхонь каналів і сумарної площі камер гідростатичного піджиму.

Таким чином, конструктивно закладаючи сумарні площі каналів i камер гідростатичного піджиму в пружнодемпфуючому елементі пластини компенсації торцевого зазору, ми можемо задавати значення сили притискання $\left(N_{n p}\right)$.

В свою чергу сила відтискання $\left(N_{\text {від }}\right)$ визначиться за виразом:

$$
N_{\text {від }}=F_{\text {мп }}+S_{n л} \cdot P_{\text {нм }},
$$

де $F_{\text {мn }}$ - сила несучої здатності масляної плівки робочої рідини в торцевому зазорі, H;

$S_{n л}$ - площа ділянок робочої поверхні пластини компенсації торцевого зазору, на які діє робоча рідина з камери високого тиску насоса, $\mathbf{m}^{2}$;

$P_{\text {нм }}$ - значення тиску в зоні високого тиску насоса підживлення, МПа.

Аналіз виразу (4) показує, що значення фізичних величин, які входять до нього в основному мають постійні значення, які легко можуть бути визначені з врахуванням фізичних властивостей робочої рідини та геометричних розмірів ділянок робочої поверхні пластини компенсації торцевого зазору, на які діє робоча рідина з камери високого тиску насоса, за умови, що агрегати експлуатуються в відповідності до технічних вимог, які висуваються для них. 
Таким чином, визначивши значення сили відтискання $\left(N_{\text {від }}\right)$, яка діє на пластину, ми можемо задати значення сили притискання $\left(N_{n p}\right)$ на пластину, яке б відповідало відношенню $N_{n p} / N_{\text {від }} \leq 1,0$. При даному співвідношенню сил, мінімальне значення торцевого зазору буде формуватися силою несучої здатності масляної плівки і силою відтискання пластини. При цьому необхідно створити такі умови, щоб перевага сил відтискання над силами притискання була мінімальною. За таких умов між поверхнями тертя в торцевому зазорі будуть створюватися умови рідинного тертя, що значно зменшить механічні втрати. Для зменшення об’ємних втрат робочої рідини необхідно, щоб мінімальний зазор формувався з врахуванням геометричного розміру абразивних частиць (50 мкм), кількість яких максимальна для десятого класу чистоти робочої рідини, на якій в відповідності до технічних вимог, експлуатуються насоси підживлення аксіально-поршневих гідромашин.

За умови, коли співвідношення складе $N_{n p} / N_{\text {від }}=1,0$, величина мінімального торцевого зазору буде формуватися силою несучої здатності масляної плівки робочої рідини в зазорі. Для даної умови буде характерним те, що за умови, коли насоси підживлення експлуатуються на забруднених рідинах, в яких геометричні розміри абразивних частиць більше розміру торцевого зазору, сформованого товщиною масляної плівки, буде інтенсивно проходити гідроабразивне спрацювання робочих поверхонь деталей в торцевому зазорі, обумовлюючи при цьому зростання механічних і об’ємних втрат в насосі.

При реалізації, для компенсації торцевого зазору, співвідношення сил, коли $N_{n p} / N_{\text {вid }} \succ 1,0$, величина зазору буде залежати від того, на яку величину сили притискання будуть перевищувати сили відтискання. За умови, коли сили притискання будуть суттєво перебільшувати сили відтискання, на формування зазору почне більш суттєво впливати сила несучої здатності масляної плівки. Подальше зростання сил притискання може супроводжуватися видавлюванням масляної плівки iз торцевого зазору, що приведе до появи металевого контакту в спряженні, інтенсивного зношення робочих поверхонь деталей і зростання механічних втрат.

За умови, коли сили притискання будуть мінімально відрізнятися від сили відтискання, тобто $N_{n p} / N_{\text {вiд }} \geq 1,0$, на формування торцевого зазору також в першу чергу буде впливати сила несучої здатності масляної плівки. Для даного випадку величина торцевого зазору буде залежати від демпфіруючої здатності мастила.

Запропонована конструкція системи компенсації торцевого зазору в качаючому вузлі насоса підживлення вигідно відрізняється від існуючих конструктивних рішень тим, що застосування пружнодемпфуючого елементу в пластині компенсації торцевого зазору дає можливість поглинати вібраційні навантаження, які виникають при статодинамічному режимі роботи качаючого вузла, що зменшує інтенсивність зношення робочих поверхонь деталей і збільшує ресурс насоса. Крім того, він 
короткочасно розвантажує роботу деталей спряження, які формують торцевий зазор, при потраплянні до нього абразивної частиці, геометричні розміри якої більші за значення його зазору, що зменшує гідроабразивне спрацювання і підвищує довговічність насосу.

\section{Висновки}

1. Запропонована конструкція компенсації торцевого зазору, що складається 3 робочої поверхні і пружнодемпфуючого елемента, у якому додатково розташовані канали й камери гідростатичного піджиму, при цьому камери гідростатичного піджиму розміщені по колу через 90 і з’єднані між собою каналами, отвори яких сполучені з камерою нагнітання.

2. Проведений аналіз сил, які впливають на величину торцевого зазору, показав, що для забезпечення ефективної роботи запропонованої системи компенсації об’ємних втрат співвідношення сил притискання і відтискання, які діють на пластину компенсації торцевого зазору, повинно відповідати наступній умові $\frac{N_{n p}}{N_{\text {від }}} \leq 1,0$.

3. Для зменшення об’ємних втрат робочої рідини через торцевий зазор необхідно, щоб мінімальний зазор формувався з врахуванням геометричного розміру абразивних частиць (50 мкм), кількість яких максимальна для десятого класу чистоти робочої рідини, на якій в відповідності до технічних вимог, експлуатуються насоси підживлення аксіально-поршневих гідромашин.

4. Застосування пружнодемпфуючого елементу в пластині компенсації торцевого зазору зменшує імовірність появи металевого контакту між робочими поверхнями деталей при неврівноважених навантаженнях на ведений вал насоса, що забезпечить збільшення його довговічності.

\section{ЛITEPATУРA}

1. Лосіков О. М. Вид та характер зношення деталей качаючого вузла насоса підживлення аксіально-поршневої гідромашини. Металлургическая и горнорудная промышленность. 2015. №7. С. 170-173.

2. Мельянцов П. Т., Лосіков О. М. Вплив торцевого зазору качаючого вузла насоса підживлення гідроприводу трансмісії ГСТ-90 на сумарні об'ємні втрати. Металлургическая и горнорудная промышленность. 2015. №7. С. 174-177.

3. Юдин Е. М. Шестеренные насосы. - М.: Машиностроение, 1964. 235 с.

4. Ачкасов К. А. Справочник начинающего слесаря: Ремонт, регулирование приборов системы питания и гидросистемы тракторов, автомобилей, комбайнов -2-е изд. перер. и доп. [Текст] / К. А. Ачкасов, В. П. Вегера - М.: Агропромиздат, 1987.-352 с.

5. Мельянцов П. Т. Опыт ремонта гидропривода ГСТ-90 на ремонтных предприятиях [Текст] / П. Т. Мельянцов, Б. Г. Харченко, И. Г. Голубев. - М.: АгроНИИТЭИИТО, 1989. $42 \mathrm{c.}$ 
6. Немировский И. А. Гидроприводы сельскохозяйственных машин [Текст] / И. А. Немировский, В. Ф. Маркин, Л. П. Середа - К.: «Техніка», 1979. -139 с.

7. Барышев В. И. Повышение надежности и долговечности гидросистем тракторов и дорожно-строительных машин в эксплуатации [Текст] / В. И. Барышев - Челябинск: Южно - Уральское книжное изд., 1973. - 110 с.

\section{REFERENCES}

1. Losikov O. M. Vyd ta kharakter znoshennia detalei kachaiuchoho vuzla nasosa pidzhyvlennia aksialno-porshnevoi hidromashyny. Metallurhycheskaia y hornorudnaia promыshlennost. 2015. №7. S. 170-173.

2. Meliantsov P. T., Losikov O. M. Vplyv tortsevoho zazoru kachaiuchoho vuzla nasosa pidzhyvlennia hidropryvodu transmisii HST-90 na sumarni obiemni vtraty. Metallurhycheskaia y hornorudnaia prombshlennost. 2015. №7. S. 174-177.

3. Yudin E. M. Shesterennyie nasosyi. - M.: Mashinostroenie, 1964. 235 s.

4. Achkasov K. A. Spravochnik nachinayuschego slesarya: Remont, regulirovanie priborov sistemyi pitaniya i gidrosistemyi traktorov, avtomobiley, kombaynov -2-e izd. perer. i dop. [Tekst] / K. A. Achkasov, V. P. Vegera - M.: Agropromizdat, 1987.-352 s.

5. Melyantsov P. T. Opyit remonta gidroprivoda GST-90 na remontnyih predpriyatiyah [Tekst] / P. T. Melyantsov, B. G. Harchenko, I. G. Golubev. - M.: AgroNIITEIITO, 1989. - 42 s.

6. Nemirovskiy I. A. Gidroprivodyi selskohozyaystvennyih mashin [Tekst] / I. A. Nemirovskiy, V. F. Markin, L. P. Sereda - K.: «TehnIka», 1979. -139 s.

7. Baryishev V. I. Povyishenie nadezhnosti i dolgovechnosti gidrosistem traktorov i dorozhno-stroitelnyih mashin $\mathrm{v}$ ekspluatatsii [Tekst] / V. I. Baryishev - Chelyabinsk: Yuzhno - Uralskoe knizhnoe izd., 1973. - 110 s.

Received 17.01.19

\section{DESIGN SOLUTIONS FOR REDUCTION OF VOLUMETRIC LOSS OF OPERATING FLUID IN GEAR-TYPE FLUID MAKEUP PUMP OF SWASH PLATE TYPE FLUID MACHINES}

The research was carried out on the operational reliability of fluid makeup pumps, the results of which concluded that it is necessary to develop design solutions for reduction of volumetric loss of operating fluid in gear-type fluid makeup pump of swash plate type fluid machines. The purpose of research is to increase operational durability of fluid makeup pump of swash plate type fluid machines by developing design solutions for reduction of volumetric loss in its pumping unit. A method is proposed for compensation of the end clearance using an end clearance compensation plate, which consists of a functional surface and an elastic-damping element, in which channels and chambers of hydrostatic lift are additionally located. The analysis of the forces that act on the end clearance compensation plate is made and their optimal ratio is substantiated, which ensures the value of the end clearance, that causes the minimum volumetric loss of the operating fluid in the pumping unit of the fluid makeup pump and increases its operational durability.

Keywords: volumetric loss, fluid makeup pump, durability 


\section{КОНСТРУКТИВНЫЕ РЕШЕНИЯ ПО СНИЖЕНИЮ ОБЪЕМНЫХ ПОТЕРЬ РАБОЧЕЙ ЖИДКОСТИ В ШЕСТЕРЕННЫХ НАСОСАХ ПОДПИТКИ АКСИАЛЬНО-ПОРШНЕВЫХ ГИДРОМАШИН}

Рассматриваются конструктивные решения по снижению объемных потерь рабочей жидкости в шестеренных насосах подпитки аксиально-поршневых гидромашин. Предложен способ компенсации торцевого зазора с применением пластины компенсации торцевого зазора, которая состоит из рабочей поверхности и упругодемпфирующего элемента, в котором дополнительно расположенные каналы и камеры гидростатического поджима. Проведен анализ сил, которые действуют на пластину компенсации торцевого зазора и обоснованно их оптимальное соотношение, которое обеспечивает величину торцевого зазора, что обусловливает минимальные объемные потери рабочей жидкости в качающем узле насоса подпитки и обеспечивает увеличение его эксплуатационной долговечности.

Ключевые слова: объемные потери, насос подпитки, долговечность.

Мельянцов Петро Тимофійович - к.т.н., доцент, кафедра надійності і ремонту машин, Дніпровський державний аграрно-економічний університет.

Melyantsov Petr T. - Ph.D., associate professor, department of reliability and repair of machines, Dnipro State Agrarian-Economic University.

Лосіков Олександр Михайлович - старший викладач, кафедра колісних та гусеничних транспортних засобів, Національна металургійна академія України.

Losikov Olexander M. - senior lecturer, department of wheeled and full-track vehicles, National Metallurgical Academy of Ukraine.

Мовчан Віталій Федорович - к.т.н., доцент, кафедра машиновикористання в землеробстві, Таврійський державний агротехнологічний університет.

Movchan Vitaliy F. - Ph.D., associate professor, department of machine utilization in agriculture, Tavria State Agrotechnological University. 